Why this matters

What happened are read down and given effect so as to be compatible with LCR and CCP's rights under Article 10.

Silber J therefore refused LCR and CCP's application for judicial review.

The 2003 Act criteria are intended to be free of content bias. However, inevitably it comes down to a judgement call as to which side of the line an advertisement will fall in any given circumstances. Unfortunately, Article 10 provides no guidance in such situations.

Accordingly, we are left with the unsatisfactory situation where the House of Lords in Animal Defenders concluded that the 2003 Act does not infringe Article 10 and where the Strasbourg court in VgT Verein Gegen Tierfabriken v Switzerland (2002) 34 EHRR 4 concluded in factually similar circumstances that Article 10 was infringed. No doubt this is why Animal Defenders have considered it necessary to appeal to Strasbourg.

A broader point is that this case again asks the question whether any form of issue-driven speech cannot be political when 'political' is so broadly defined in the 2003 Act.

The full case citation is as follows:

London Christian Radio \& Anor, R (on the application of) v Radio Advertising Clearance Centre \& Anor [2012] EWHC 1043 (Admin) (20 April 2012).

Dr Catherine Lee, Solicitor, Osborne Clarke, Thames Valley

E-mail: catherine.lee@osborneclarke.com

\section{OFT extracts undertakings from affiliate marketer MoreNiche}

\section{Manana Shrimpling}

Journal of Direct, Data and Digital Marketing Practice (2012) 14, 71-72. doi:10.1057/dddmp.2012.19

Topic: Health \& Beauty

Who: OFT and MoreNiche Ltd

Where: London

When: 25 April 2012

Law as stated at: 1 May 2012

The Office of Fair Trading (OFT) has accepted legal undertakings from online affiliate marketing operator MoreNiche Limited (MoreNiche) to address concerns about the way affiliates in MoreNiche's network market and promote health and beauty products.

Each affiliate agreed with MoreNiche to include a link on the affiliate's website to a product merchant's site. In return, the affiliate received a commission for every sale made after clicking on the link. 
MoreNiche's network brings together 30 product merchant businesses and over 149,000 affiliates. In this case, the products in question included diet aids and teeth-whitening products.

The OFT had concerns in relation to some of the affiliate marketing. In particular, it identified that reviews and product endorsements on the affiliates' websites were presented as independent consumer reviews when in fact they were commercial promotions.

The websites also did not make it clear that the affiliate would be financially rewarded for purchases made by consumers that the affiliate introduced to MoreNiche merchants. The OFT took the view that consumers are more likely to be influenced to buy products based on apparently unbiased reviews.

Following its investigation, the OFT concluded that breaches of the Consumer Protection from Unfair Trading Regulations 2008 (CPRs) may have occurred due to the following commercial practices:

- the promotions did not disclose material information (ie that the promotion had been paid for or otherwise remunerated), or provided information that was unclear, unintelligible, ambiguous or untimely, and were therefore contrary Regulation 3(4)(b) of the CPRs;

- editorial content was used to promote a product where the promotion had been paid for, without making it clear that the promotion had been paid for in the content, contrary to Paragraph 11 of Schedule 1 of the CPRs; and

- the promotions falsely claimed or created the impression that the affiliate was not acting for purposes relating to its business, or falsely represented the affiliate as a consumer, contrary to Paragraph 22 of Schedule 1 of CPRs.

The undertakings given by MoreNiche require it to take sufficient steps within agreed timescales to ensure that affiliates do not continue or repeat such conduct when promoting MoreNiche merchants' products. For example, promotions must include a prominently displayed statement that would be unavoidable for the average consumer, stating that the promotion has been paid for or otherwise remunerated. MoreNiche has also agreed to provide guidance notes to affiliates in relation to their legal responsibilities.

The nature of the undertakings given by MoreNiche will be of interest to other affiliate network operators who want to ensure that they and their affiliates are complying with the law. They highlight the responsibility of MoreNiche, as the operator of the affiliate network, to take sufficient, reasonably practisable steps to ensure that the affiliates within its network do not engage in unfair commercial practices when promoting products of MoreNiche merchants.

Manana Shrimpling, Solicitor, Osborne Clarke

E-mail: manana.shrimpling@osborneclarke.com 